\title{
Influence of Foaming Agent on Technical Performance of Ceramsite Aerated Concrete Blocks
}

\author{
Yanhong Wang*, Yuping Wu, Chaocan Zheng, Zhanghangzhi Luo, Min Zhou
}

Jinhua Polytechnic, Jinhua 321007, China

Corresponding Author Email: yyh527@163.com

https://doi.org/10.18280/acsm.430512

Received: 28 April 2019

Accepted: 19 July 2019

\section{Keywords:}

ceramsite aerated concrete (CAC) blocks, foaming agent, mix ratio, technical performance

\begin{abstract}
The dosage of the foaming agent directly affects the technical performance of ceramsite aerated concrete (CAC). If the dosage is improper, the CAC will be difficult to prepare and unstable in technical performance. To improve the quality of the CAC blocks, this paper aims to disclose how the mix ratio of foaming agent affects the technical performance of the CAC blocks through experiments. Specifically, the CA5.0B07 CAC blocks were selected as the research object. The following indices were identified to characterize the technical performance of the CAC blocks, including workability, dry density, water absorption, compressive strength and thermal conductivity. Several CAC blocks were prepared with different mix ratios of the foaming agent: $0.05 \%, 0.10 \%, 0.15 \%, 0.20 \%$ and $0.25 \%$. The mix ratios were determined empirically, and refer to the mass percentage of the foaming agent in the binding material. In addition, the linear interpolation was adopted to determine the rational interval of foaming agent dosage for the CAC blocks. The results show that the CAC blocks reached the technical levels for qualified product in current standards when the mix ratio of the foaming agent fell within $0.13 \% \sim 0.23 \%$, and those for superior product when the latter fell within $0.15 \% \sim 0.20 \%$. The research results provide a technical guide for actual production of the CAC blocks, and promotes the application of these blocks in the construction of energyefficient buildings.
\end{abstract}

\section{INTRODUCTION}

The ceramsite aerated concrete (CAC) blocks are manufactured in multiple steps. First, cement and fly ash, as the binding materials, are prepared into a slurry with foaming agent and water. Then, lightweight ceramsite is added into the slurry as aggregate with a volume ratio of no less than $40 \%$. The mixture will then be subjected to mechanical stirring, vibration casting, steam curing and cutting [1]. This novel selfinsulating wall material has been favored by the construction industry, because it is light, strong, highly impermeable, unlikely to shrink or conduct heat, yet easy to construct [2-4]. With the growing demand for energy-efficient buildings, many countries around the world have attached great importance to the development and application of the CAC blocks $[5,6]$.

The existing studies have mainly explored the mix ratio of the CAC and its blocks, especially the ratios of raw materials like cement, fly ash, ceramsite and water, as well as the manufacturing technique, production equipment and the influencing factors of the CAC's technical performance. The previous research on the foaming agent of the CAC stops at the theoretical analysis on the concept, type, foaming mechanism, performance and applications of the foaming agent [7-9]. Only a few scholars have tested how the foaming agent affects the strength, setting time, apparent density and water consumption for standard consistency of the CAC matrix $[10,11]$. However, there is virtually no report on the influence of the foaming agent on the technical performance of the CAC.
Being a key raw material of the CAC blocks, the foaming agent directly bears on the technical performance of the blocks, ranging from dry density, water absorption, compressive strength to thermal conductivity $[7,10]$. In actual production of the CAC blocks, the mix ratio of the foaming agent is generally determined empirically. If the mix ratio is too low, the foaming agent cannot fully give play to the advantages of the CAC blocks, namely, lightweight, small shrinkage, low thermal conductivity, strong impermeability and ease of construction. If the mix ratio is too high, much of the foaming agent will be wasted, pushing up the production cost and reducing the strength of the $\mathrm{CAC}$ blocks.

This paper aims to disclose how the mix ratio of foaming agent affects the technical performance of the CAC blocks. Considering the actual production conditions, the CA5.0B07 CAC blocks were selected as the research object, because CA5.0B07 CAC is the most widely used type of the CAC. The following indices were identified to characterize the technical performance of the CAC blocks, including workability, dry density, water absorption, compressive strength and thermal conductivity. Several CAC blocks were prepared with different mix ratios of the foaming agent: $0.05 \%, 0.10 \%$, $0.15 \%, 0.20 \%$ and $0.25 \%$. The mix ratios were determined empirically, and refer to the mass percentage of the foaming agent in the binding material. Through experiments on the blocks, the author determined the rational mix ratio of the foaming agent in the CAC blocks. The research results provide theoretical and practical guidance on the development, production and application of the CAC blocks, laying the basis for the research and design of green, low-carbon and energyefficient building materials. 


\section{METHODOLOGY}

\subsection{Experimental materials}

(1) Ceramsite

The CA5.0B07 CAC blocks were prepared with Grade 400 spherical ceramsite. Table 1 provides the main technical parameters of the ceramsite.

(2) Cement

The Conch ordinary Portland cement 42.5 was selected to prepare our test blocks. Table 2 lists the main technical parameters of the cement.

Table 1. Main technical parameters of the ceramsite

\begin{tabular}{|c|c|c|c|c|}
\hline Type & $\begin{array}{c}\text { Grain size } \\
/ \mathbf{m m}\end{array}$ & $\begin{array}{c}\text { Bulk density } \\
/\left(\mathbf{k g} \cdot \mathbf{m}^{-\mathbf{3}}\right)\end{array}$ & 1h water absorptivity $/ \%$ & $\begin{array}{c}\text { Compressive strength of concrete } \\
\text { cylinder } / \mathbf{M P a}\end{array}$ \\
\hline $\begin{array}{c}\text { Grade } 400 \text { spherical } \\
\text { ceramsite }\end{array}$ & $5-20$ & 365 & 2.13 & 1.4 \\
\hline
\end{tabular}

Table 2. Main technical parameters of the cement

\begin{tabular}{|c|c|c|c|c|c|c|}
\hline \multirow{2}{*}{ Fineness/\% } & \multirow{2}{*}{ Initial setting time /min } & \multirow{2}{*}{ Final setting time /min } & \multicolumn{2}{|c|}{ Compressive strength /MPa } & \multicolumn{2}{|c|}{ Bending strength /MPa } \\
\cline { 4 - 7 } & & & $3 \mathrm{~d}$ & $28 \mathrm{~d}$ & $3 \mathrm{~d}$ & $28 \mathrm{~d}$ \\
\hline 2.2 & 145 & 340 & 25.7 & $\geq 42.5$ & 5.7 & $\geq 6.3$ \\
\hline
\end{tabular}

(3) Fly ash

Grade II fly ash was added to replace some of the cement to save the cost and fill up the gaps in the test blocks. Table 3 shows the main technical parameters of the fly ash.

Table 3. Main technical parameters of the fly ash

\begin{tabular}{|c|c|c|c|c|c|}
\hline \multirow{2}{*}{ Fineness /\% } & \multirow{2}{*}{ Water demand /\% } & \multirow{2}{*}{ Loss on ignition /min } & Water content $/ \%$ & \multicolumn{2}{|c|}{ Strength activity index $/ \%$} \\
\cline { 4 - 6 } & & 2.78 & 0.06 & 78 & 96 \\
\hline 3.35 & 86.5 & $\mathrm{~d}$ & $\mathrm{~d}$ & 78 \\
\hline
\end{tabular}

(4) Foaming agent

HTW-1 high-efficiency composite foaming agent was adopted for our experiments. The main technical parameters of the foaming agent are displayed in Table 4.

Table 4. Main technical parameters of the foaming agent

\begin{tabular}{|c|c|c|c|c|}
\hline pH & Expansion ratio & Density $/\left(\mathbf{k g} \cdot \mathbf{m}^{-\mathbf{3}}\right)$ & 1h settlement $/ \mathbf{m i n}$ & 1h bleeding/mL \\
\hline $6-7$ & 35 & $950-1150$ & 8 & 17 \\
\hline
\end{tabular}

\subsection{Experimental plan}

(1) According to the Ceramsite Aerated Concrete Block
(JG/T504-2016), the technical performance standard for the CA5.0B07 CAC blocks is presented in Table 5.

Table 5. Technical performance standard for the CA5.0B07 CAC blocks

\begin{tabular}{|c|c|c|c|c|c|}
\hline \multicolumn{2}{|c|}{ Dry density /kg.m-3 } & \multirow[b]{2}{*}{$\begin{array}{c}\text { Water } \\
\text { absorption } / \%\end{array}$} & \multicolumn{2}{|c|}{ Strength /MPa } & \multirow[b]{2}{*}{ Thermal conductivity $/ \mathbf{W}(\mathbf{m} \cdot \mathbf{K})^{-1}$} \\
\hline $\begin{array}{c}\text { Superior } \\
\text { product }\end{array}$ & $\begin{array}{c}\text { Qualified } \\
\text { product }\end{array}$ & & $\begin{array}{r}\text { Superior } \\
\text { product }\end{array}$ & $\begin{array}{c}\text { Qualified } \\
\text { product }\end{array}$ & \\
\hline$\leq 725$ & $\leq 750$ & $\leq 35$ & $\geq 7.5$ & $\geq 5.0$ & $\leq 0.18$ \\
\hline
\end{tabular}

(2) According to the mix ratio design in the Technical Specification for Lightweight Aggregate Concrete (JGJ512002), the mix ratios of the CA5.0B07 CAC blocks were designed (Table 6). Note that the mix ratio of the foaming agent refers to its mass percentage in the binding material.

Table 6. Mix ratios of the test groups

\begin{tabular}{|c|c|c|c|c|c|c|}
\hline \multirow[b]{2}{*}{ Group number } & \multirow{2}{*}{ Ceramsite $/\left(\mathbf{k g} \cdot \mathbf{m}^{-3}\right)$} & \multirow{2}{*}{ Cement $/\left(\mathrm{kg} \cdot \mathrm{m}^{-3}\right)$} & \multirow{2}{*}{ Fly ash $/\left(\mathrm{kg} \cdot \mathrm{m}^{-3}\right)$} & \multirow{2}{*}{ Water $/\left(\mathbf{k g} \cdot \mathbf{m}^{-3}\right)$} & \multicolumn{2}{|c|}{ Foaming agent } \\
\hline & & & & & Dosage $/\left(\mathrm{kg} \cdot \mathrm{m}^{-3}\right)$ & Mix ratio $/ \%$ \\
\hline 1 & 268 & 232 & 169 & 153 & 0.20 & 0.05 \\
\hline 2 & 268 & 232 & 169 & 153 & 0.40 & 0.10 \\
\hline 3 & 268 & 232 & 169 & 153 & 0.60 & 0.15 \\
\hline 4 & 268 & 232 & 169 & 153 & 0.80 & 0.20 \\
\hline 5 & 268 & 232 & 169 & 153 & 0.10 & 0.25 \\
\hline
\end{tabular}

(3) The raw materials were weighted accurately according to the mix ratio of the corresponding test group. First, the cement and fly ash were dry-mixed for $60 \mathrm{~s}$, and then mixed with water for $150 \mathrm{~s}$. Next, the foaming agent was added to the mixture and blended for $10 \mathrm{~s}$. Finally, the preprocessed ceramsite was added, followed by a 15 s stirring $[12,13]$. The 
workability of the mixture in each test group was measured, and a specified number of test blocks were prepared according to the preset technical indices.

(4) According to the Test Methods of Autoclaved Aerated Concrete (GB/T11969-2008) and the Thermal Insulation Determination of Steady-State Thermal Resistance and Related Properties: Guarded Hot Plate Apparatus (GB/T10294-2008), the test blocks in each group were cured under standard conditions to the required ages. Then, the dry density, water absorption, compressive strength and thermal conductivity of each group were measured.

\section{EXPERIMENTAL RESULTS AND DISCUSSION}

\subsection{Influence of foaming agent on workability of the CAC}

The workability of the CAC mixture for each test group was measured by the slump of fluidity (Figure 1). The results show that the CAC mixtures of all groups achieved the required cohesiveness and water-holding capacity.

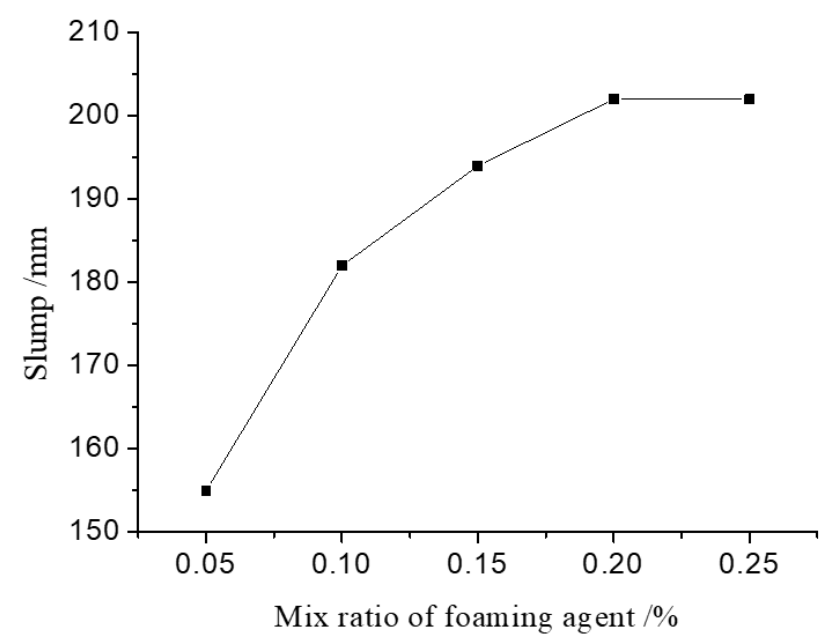

Figure 1. Influence of foaming agent on fluidity of the CAC

As shown in Figure 1, with the growing dosage of the foaming agent, the fluidity slump of the CAC mixture increased first and then tended to stable, showing an overall increasing trend. The reason is that, under the constant waterbinder ratio, the bubbles created by the foaming agent work like balls that reduce the frictional resistance within the mixture, thus improving the fluidity. The bubbles also prevent the ceramic particles from floating and the moisture from descending. In this way, the mixture is less like to get delaminated and dissociated or bleed water, showing a better workability $[14,15]$. The overall workability of the CAC mixture was good, with a slump greater than $150 \mathrm{~mm}$, when the mix ratio of the foaming agent fell between $0.05 \%$ and $0.25 \%$. Hence, the mix ratio in this value range satisfies the requirements of actual production.

\subsection{Influence of foaming agent on dry density of the CAC blocks}

Three $100 \mathrm{~mm} \times 100 \mathrm{~mm} \times 100 \mathrm{~mm}$ CAC blocks were prepared for each test group to measure the influence of foaming agent on dry density. The dry density was measured according to the specified method. The measured results are shown in Figure 2 below.

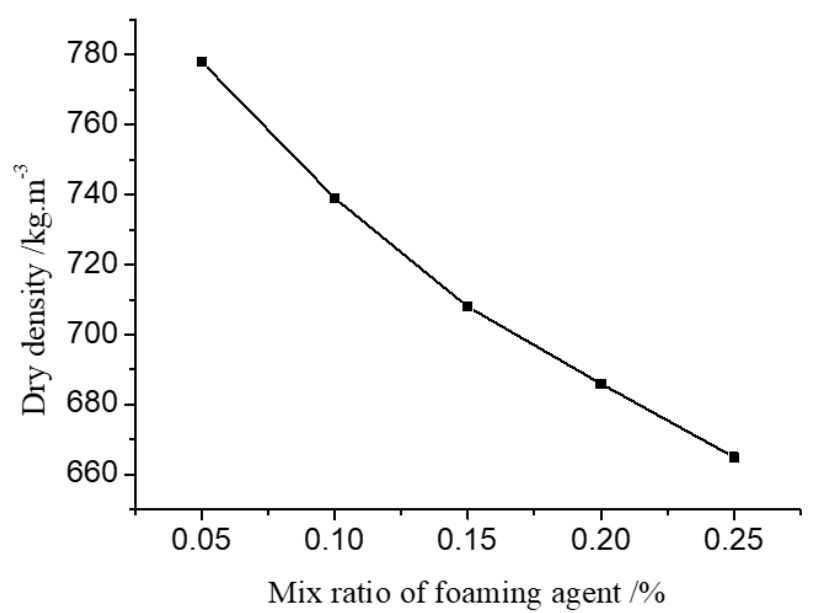

Figure 2. Influence of foaming agent on dry density of the CAC blocks

As shown in Figure 2, with the growing dosage of the foaming agent, the dry density of each CAC block declined. This trend can be explained as follows. More bubbles are created with the growth in the dosage of the foaming agent. As a result, gas content, expansion degree and porosity are all on the rise. Thus, the test block will expand in size, reducing the dry density $[16,17]$. Through linear interpolation, it is learned that the dry density of the CAC block reached the level for qualified product $\left(<750 \mathrm{~kg} \cdot \mathrm{m}^{-3}\right)$, when the mix ratio of the foaming agent was above $0.09 \%$, and reached the level for superior product $\left(<725 \mathrm{~kg} \cdot \mathrm{m}^{-3}\right)$, when the mix ratio of the foaming agent was above $0.12 \%$.

\subsection{Influence of foaming agent on water absorption of the CAC blocks}

Three $100 \mathrm{~mm} \times 100 \mathrm{~mm} \times 100 \mathrm{~mm}$ CAC blocks were prepared for each test group to measure the influence of foaming agent on water absorption. The water absorption was measured according to the specified method. The measured results are shown in Figure 3 below.

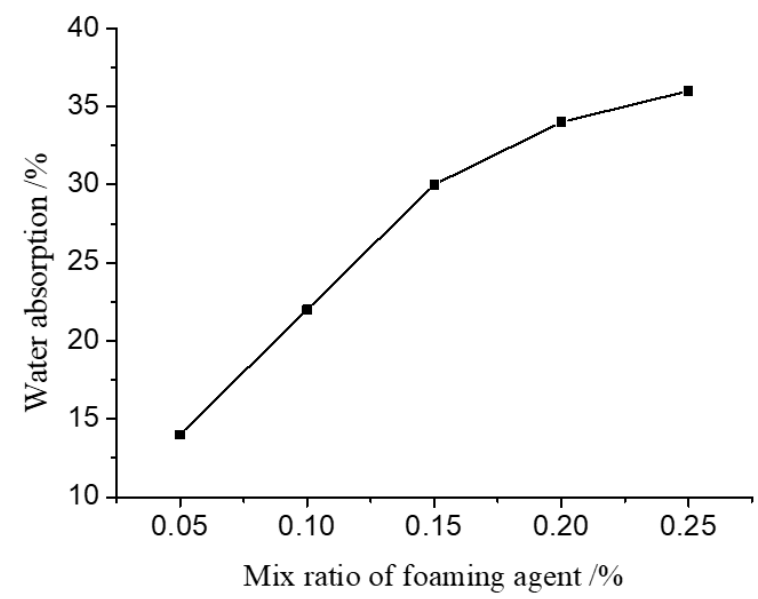

Figure 3. Influence of foaming agent on water absorption of the CAC blocks

As shown in Figure 3, with the growing dosage of the foaming agent, the water absorption of each CAC block increased. This is because the rising dosage of foaming agent pushes up the bubble size, porosity, and the number of pores 
induced by the bubbles in the CAC block. Hence, the block can absorb more water [11]. Linear interpolation results show that, when the mix ratio of the foaming agent was below $0.23 \%$, the water absorption of the CAC block was smaller than or equal to $35 \%$, which meets the requirements in relevant standards.

\subsection{Influence of foaming agent on compressive strength of the CAC blocks of different ages}

Nine $150 \mathrm{~mm} \times 150 \mathrm{~mm} \times 150 \mathrm{~mm}$ CAC blocks were prepared for each test group to measure the influence of foaming agent on compressive strength of the CAC blocks of different ages. The compressive strength was measured at $3 \mathrm{~d}, 7 \mathrm{~d}$ and $28 \mathrm{~d}$, respectively, according to the specified method. The measured results are shown in Figure 4 below.

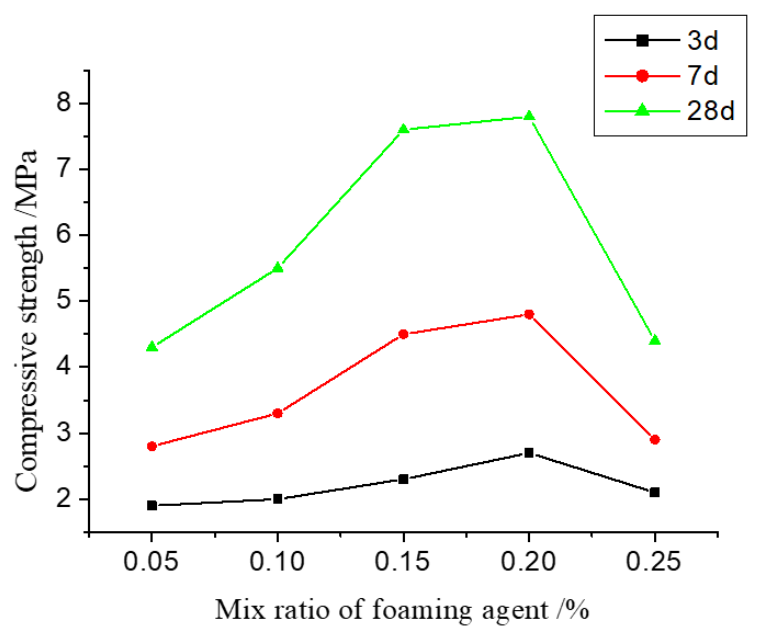

Figure 4. Influence of foaming agent on compressive strength of the CAC blocks of different ages

As shown in Figure 4, the compressive strength of the CAC increased with the curing age, owing to the continued growth in the amount of hydrates produced through the hydration of cement over the curing period. With the growing dosage of the foaming agent, the $3 \mathrm{~d}, 7 \mathrm{~d}$ and $28 \mathrm{~d}$ compressive strengths of each test block all increased first and then plunged. The peak strengths were observed when the foaming agent reached the mix ratio of $0.20 \%$. This phenomenon is attributable to the following factors. In general conditions, the ceramsite can absorb lots of water, while the foaming agent has a certain water reducing effect on the $\mathrm{CAC}$ mixture; when a few amount of the foaming agent is added, the water reducing effect can offset the water absorption of the ceramsite, boosting the compressive strength of the test block; when a huge amount of the foaming agent is added, the bubble size and porosity of the test block will increase, reducing the compressive strength [18, 19]. Through linear interpolation, it is obtained that the $28 \mathrm{~d}$ compressive strength of the CAC block reached the level for qualified product $(>5.0 \mathrm{MPa})$, when the mix ratio of the foaming agent fell between $0.08 \%$ and $0.24 \%$, and reached the level for superior product $(>7.5 \mathrm{MPa})$, when the latter fell within $0.15 \% \sim 0.20 \%$.

\subsection{Influence of foaming agent on thermal conductivity of the CAC blocks}

Four $300 \mathrm{~mm} \times 300 \mathrm{~mm} \times 30 \mathrm{~mm}$ CAC blocks were prepared for each test group to measure the influence of foaming agent on thermal conductivity of the CAC blocks. The thermal conductivity was measured according to the specified method. The measured results are shown in Figure 5 below.

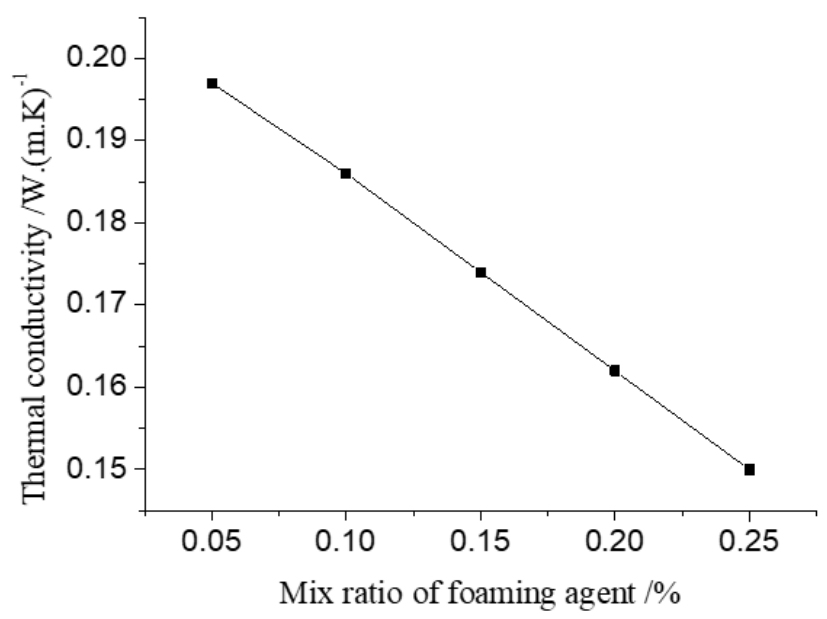

Figure 5. Influence of foaming agent on thermal conductivity of the CAC blocks

As shown in Figure 5, with the growing dosage of the foaming agent, the thermal conductivity of each CAC block was decreasing. The falling thermal conductivity is the result of the growth in the number of bubbles and in the porosity within the block, as more and more foaming agent is introduced [20, 21]. The results of linear interpolation show that the thermal conductivity satisfied the requirements $(\leq 0.18$ $\left.\mathrm{W} \cdot(\mathrm{m} \cdot \mathrm{K})^{-1}\right)$ in relevant standards, when the mix ratio of the foaming agent was above $0.13 \%$.

\section{CONCLUSIONS}

(1)Under the conditions of our experiments, when the mix ratio of the foaming agent increased from $0.05 \%$ to $0.25 \%$, the slump of the CAC mixture increased first and then tended to stable, showing an overall increasing trend; the water absorption of the CAC blocks exhibited an increasing trend; the dry density and thermal conductivity of the blocks were both on the decline; the compressive strength of the blocks increased before a decline.

(2) When the mix ratio of the foaming agent fell within $0.13 \%$ and $0.23 \%$, the technical indices of the CAC blocks, namely, dry density, water absorption, compressive strength and thermal conductivity, all met the levels for qualified product in the Ceramsite Aerated Concrete Block (JG/T5042016).

(3) When the mix ratio of the foaming agent fell within $0.15 \% \sim 0.20 \%$, the technical indices of the CAC blocks, namely, dry density, water absorption, compressive strength and thermal conductivity, all met the levels for superior products in the Ceramsite Aerated Concrete Block (JG/T5042016).

(4) Compared with other raw materials, the foaming agent accounts for a small portion in the CAC blocks. Despite its small presence, the foaming agent is a key influencing factor of the technical performance of the CAC blocks. Our research method and results provide a technical guide for actual production of the CAC blocks, and promotes the application of these blocks in the construction of energy-efficient buildings. 


\section{ACKNOWLEDGMENT}

This paper is supported by the Scientific Research Fund of Zhejiang Provincial Department of Education (Grant No: Y201941603); Public Welfare Science and Technology Research Program of Jinhua (Grant No: 2018-4-002).

\section{REFERENCES}

[1] Namsone, E., Sahmenko, G., Namsone, E., Korjakins, A. (2018). Research on properties of high performance foamed concrete. Key Engineering Materials, 788: 13-22. https://doi.org/10.4028/www.scientific.net/KEM.788.13

[2] Tan, C.L., Deng, Y., Ren, J., Qin, W.Y., Jiang, W.C., Huang, F.R., Zeng, X. (2018). Study on the mechanical and thermal properties of lightweight and high-strength ceramsite aerated concrete. New Building Materials, 45(5): 109-112, 115. https://doi.org/10.3969/j.issn.1001702X.2018.05.028

[3] Amran, Y.H.M., Farzadnia, N., Ali, A.A. (2015). Properties and applications of foamed concrete; a review. Construction and Building Materials, 101(1): 990-1005. https://doi.org/10.1016/j.conbuildmat.2015.10.112

[4] Raj, A., Sathyan, D., Mini, K.M. (2019). Physical and functional characteristics of foam concrete: A review. Construction and Building Materials, 221: 787-799. https://doi.org/10.1016/j.conbuildmat.2019.06.052

[5] Allouhi, A., Fouih, Y.E., Kousksou, T., Jamil, A., Zeraouli, Y., Mourada, Y. (2015). Energy consumption and efficiency in buildings: Current status and future trends. Journal of Cleaner Production, 109(16): 118-130. https://doi.org/10.1016/j.jclepro.2015.05.139

[6] Xu, H.X., Wan, C.T., Zhang, X.Y. (2018). Development status and trend of building insulation and energy-saving wall. Block-Brick-Tile, 9: 91-92. http://doi.org/10.3969/j.issn.1001-6945.2018.09.030

[7] Xu, Y.M., Meng, H.N., Zuo, L.P., Zhu, X., Lu, X.J. (2016). Advance in foaming agent for foamed concrete. Coal Ash, 3: 43-46. https://doi.org/10.3969/j.issn.1007046X.2016.03.014

[8] Tarameshloo, A., Kani, E.N., Allahverdi, A. (2017). Performance evaluation of foaming agents in cellular concrete based on foamed alkali-activated slag. Canadian Journal of Civil Engineering, 44(11): 893-898. https://doi.org/10.1139/cjce-2016-0491

[9] Sahu S.S., Gandhi, I.S.R., Khwairakpam, S.J. (2018). State-of-the-Art Review on the Characteristics of Surfactants and Foam from Foam Concrete Perspective. Journal of The Institution of Engineers (India), 99(2): 391-405. https://doi.org/10.1007/s40030-018-0288-5

[10] Kuzielová, E., Pach, L., Palou, M. (2016). Effect of activated foaming agent on the foam concrete properties. Construction and Building Materials, 125: 998-1004. https://doi.org/10.1016/j.conbuildmat.2016.08.122
[11] Qiao, H.H., Li, J. (2017). Study on influence of mineral foaming agent on the property of foamed concrete basis materials. New Building Materials, 44(6): 130-133. https://doi.org/10.3969/j.issn.1001-702X.2017.06.036

[12] Kumar, N.V., Arunkumar, C., Senthil, S.S. (2018). Experimental study on mechanical and thermal behavior of foamed concrete. Materials Today: Proceedings, 5(2): 8753-8760. https://doi.org/10.1016/j.matpr.2017.12.302

[13] Ahmad, M.R., Chen, B. (2019). Experimental research on the performance of lightweight concrete containing foam and expanded clay aggregate. Composites Part B: Engineering, 171: 46-60. https://doi.org/10.1016/j.compositesb.2019.04.025

[14] Ahmad, M.R., Chen, B., Shah, S.F.A. (2019). Investigate the influence of expanded clay aggregate and silica fume on the properties of lightweight concrete. Construction and Building Materials, 220: 253-266. https://doi.org/10.1016/j.conbuildmat.2019.05.171

[15] Choi, M.I., Lee, H.S., \& Yun, C.Y. (2016). An experimental study on the influence of bubble properties of mineral and vegetable foaming agent to physical properties of cement paste using foaming agent. Journal of the Architectural Institute of Korea Structure \& Construction, 32(6): 35-42. https://doi.org/10.5659/JAIK SC.2016.32.6.35

[16] Sahmenko, G., Namsone, E., Rubenis, K., Dubnika, A., Niparts, G. (2018). Effect of various additives and aeration on the properties of lightweight concrete. Key Engineering Materials, 762: 351-355. https://doi.org/10.4028/www.scientific.net/KEM.762.35 1

[17] Falliano, D., De Domenico, D., Ricciardi, G., Gugliandolo, E. (2017). Experimental investigation on the compressive strength of foamed concrete: effect of curing conditions, cement type, foaming agent and dry density. Construction and Building Materials, 165: 735749. https://doi.org/10.1016/j.conbuildmat.2017.12.241

[18] Sayadi, A.A., Tapia, J.V., Neitzert, T.R., Clifton, G.C. (2016). Effects of expanded polystyrene (EPS) particles on fire resistance, thermal conductivity and compressive strength of foamed concret. Construction and Building Materials, 112: 716-724. https://doi.org/10.1016/j.conbuildmat.2016.02.218

[19] Su, L.J., Sun, Q., Li, S.W. (2017). Effect of mass fraction of foaming agent on the strength of fly ash concrete. NonMetallic Mines, 4: 53-55. https://doi.org/10.3969/j.issn.1000-8098.2017.04.016

[20] Meng, Y., Tian, C., Ji, X.K. (2015). Effect of foam content on thermal performance of foamed concrete. Building Energy EFFICIENCY, 2: 65-67,78. https://doi.org/10.3969/j.issn.1673-7237.2015.02.016.

[21] Batool, F., Bindiganavile, V. (2018). Quantification of factors influencing the thermal conductivity of cementbased foam. Cement and Concrete Composites, 91: 7686. https://doi.org/10.1016/j.cemconcomp.2018.04.015 